\title{
Explorative Teaching and Research-From Memory Work to Experience Stories
}

\author{
Karin Widerberg \\ Department of Sociology and Human Geography, University of Oslo, Oslo, Norway \\ Email: karin.widerberg@sosgeo.uio.no
}

Received 28 June 2016; accepted 23 August 2016; published 26 August 2016

Copyright (C) 2016 by author and Scientific Research Publishing Inc.

This work is licensed under the Creative Commons Attribution International License (CC BY).

http://creativecommons.org/licenses/by/4.0/

(c) () Open Access

\begin{abstract}
Memory work is an approach developed to help us problematize the things we take for granted and as such an invitation to methodological explorations in teaching and research. By our own stories of memories and experiences we are invited to look for variety-in our own stories as well as in relation to the stories of the others-regarding content as well as interpretations. A set of techniques is developed to make this happen, in writing as well as in analyzing. Focusing on the social aspects of a story does not only imply a possibility to connect different analytical levels (micro and macro) and verify concepts and theories. It also allows us to question or specify fixed or simplified categories and concepts by making other memories, experiences and understandings visible. As such it is an approach that stimulates creativity and knowledge production in both teaching and research, to the joy of all participants. In this article it is illustrated how the approach can be used in different settings and on different themes in both teaching and research hereby also illuminating the kinds of knowledge that can be gained. Cases and detailed accounts of how the approach can be used when teaching a one-day workshop, a three-day course but also in a two-hour lecture in a regular class on BA-level are given. Examples of the use of the approach in different research projects are also presented so as to illuminate the bridge between research and teaching and how research approaches can be made into teaching approaches. The illustrations are meant to inspire further use and development of the approach so as to fit different situations and themes in teaching and research.
\end{abstract}

\section{Keywords}

Memory Work, Experience Stories, Explorative Teaching and Research

\section{Introduction}

Within the Humanities and the Social Sciences we teach students about the human and her society, in all its va- 
riety throughout history and around the world. It is all about us yet the material used to illustrate issues and arguments are about the "others", documented through statistics, interviews, observations and so forth. To make the student relate to all this gathered knowledge and make it hers, we use ourselves as best as we can and not only intellectually. We are witty, enthusiastic, humoristic and maybe also a bit personal by telling anecdotes about ourselves. There are however also more reliable and fruitful approaches that can bridge the gaps between the "others" and us, between the students and between them and the teacher so as to enlighten us all. Memory work is such an approach that I have used extensively in class, on all levels and on all kinds of themes (see Widerberg, 2008 for an overview). Themes, number of students and time allotted, have inspired me to develop the approach so as to fit the circumstances as best as possible, from a variety of ways to do memory work to a variety of ways to write and use experience stories. In this process my use of such approaches also in my different research projects, has been a huge inspiration.

In this article I will start out with an illustration and use a case, a one-day workshop in memory-work, to explicate how it can be done and exemplify the kinds of knowledge that can be gained. A brief account of the other ways that I have used the approach when teaching and doing research, as well as theoretical reflections on memory and knowledge, will follow. First though, a few introductory words about memory work so as to make sense of the approach used in the case presented.

\section{Memory Work-The Original Approach}

Memory work was developed as a collective method by the sociologist Frigga Haug (Haug, 1987). The aim was to develop a method that would facilitate the problematization of the things we take for granted, especially gender, since it is exactly this taken-for-grantedness that contributes to making patriarchy invisible and difficult to change. But the aim was also to develop a non-positivistic research method where the division and hierarchy between researcher and research subjects were eliminated. Formulated as a feminist research method, and aiming at empowerment and liberation in both its process and results, the collective approach was underlined. Briefly, the procedures of the method were as follows.

A group of women were to decide the theme for the memory work. Once the theme was settled, different kinds of "triggers", for example photos, could be used to get the memory process started. The stories were to be written as concretely and as detailed as possible, preferably about a specific event or situation. To facilitate an observing gaze and the production of detailed accounts, the use of the form of the third person was proposed when writing the story. All the stories were then to be read and analyzed as if the author were dead (Roland Barthes' famous term), so that no one would own the (true) interpretations. Further, the aim was not to look for personal explanations but rather to look for social explanations (social relations and patterns) of what the stories could teach us about the doings of gender. To make the gender of the story visible so as to further our understanding of how gender is done, the female character in the story could be exchanged with a male, and vice versa. After a preliminary analysis, the stories could be rewritten, or new ones written, so as to get as rich and varied a picture as possible.

Haug and her fellow sisters explored and developed the method when trying to problematize the sexualization of the female body as a theme (Haug, 1987). Since then, the method has been used and explored with a variety of themes but also in a variety of different ways (see for example Kaufman et al. (2008) for a presentation of the field).

\section{A Case-Exploring Motherhood through Memory Work}

In the spring of 2013 I was a guest professor at the Morgan Center of the University of Manchester and asked to give a one-day workshop in Memory-work for their staff including PhD scholars and MA-students. Around 30 participants, aged 30 - 75 (the majority in the age group 30 - 50), all women except for three men, were there to learn about the approach of memory work.

Since the focus was on the approach and not a particular theme and we only had a day at our disposal I had decided the theme beforehand. I had chosen motherhood, knowing that all the participants were gender researchers and therefore likely to find such a theme interesting. When approaching a theme like motherhood, "other mothers", might be a way to start to explore an area as vast and complex as this one. One's own mother/mothers might be too close and vast as a field of experiences and memories, to start with. Besides, in describing other mothers, one's own mother will lurk in the background since comparisons-as will be demonstrated in 
the stories here presented—is a fundamental aspect of memory making. Further, having limited time at our disposal, the topic chosen must be formulated in such a way as to allow for short and descriptive written accounts of a particular situation.

I had previously run a similar workshop but then with only male gender researchers, on fatherhood and successfully started out with "My friend's father" (Widerberg, 2011). I decided to do the same here and chose "My friend's mother" as the theme for our memory stories. When presented it was however not met with acclamation or joyful anticipation by the participants who actually seemed rather hesitant and even reluctant. At this stage of the process participants quite often express that they do not have any memories or anything to write about no matter the theme in question. Since I was familiar with this very first reaction and knew that the atmosphere would change once they started writing and reading the stories I was confident enough to persuade them to give it a try. I knew that after some minutes of thinking the memories and stories would come to them and that the instructions I was to give them would help them get started.

Knowing from experience that the participants' resistance often is founded on doubts regarding memory and interpretation I always say a few words about it all. I accordingly stress that writing a memory always means interpretation, since interpretation is what drives the memory forward, that is, how and what we remember. Every memory has layers of interpretation, especially if the memory is of something that happened long ago. Even so, I tell them, they should try not to analyze while writing, but give the story a chance to be told as straightforwardly as possible. Concepts, hasty analyzes, immediately processing it academically-here that is more of a problem than a resource; it closes more than it opens for interpretation at this stage. Writing the stories anonymously, I further tell them, is not only, or even primarily, to facilitate the writing process; it is meant to enrich the interpretation process. The written stories are to be interpreted collectively. No one can or is then allowed to claim ownership of the story (or of the "correct" interpretation). But once the analyses have been completed, they can, if they so wish, tell each other which story was theirs.

All the steps in the process from writing to analyzing are accordingly roughly presented before we embark on the writing of stories. The participants need to feel comfortable and safe so as to be able to contribute and not feel lured into something they might regret afterwards. But they also need to understand the knowledge reasons behind the specific instructions given. So after presenting the approach of memory work, along the lines presented above, the participants were given the following instructions, handed out to them but also further explicated by me orally.

\subsection{Memory-Work Instructions (Manchester 17.5.13)}

\subsubsection{Writing (30 Minutes)}

- Write a short story of (a situation of encountering/meeting/being with)... My friend's mother.

- Use 5 - 10 minutes to think about which story to write.

- Use 20 minutes to write the story in first person (that is, I). Write as descriptive and concrete as possible, avoid interpretation and if you write about feelings try to describe them descriptively and embodied. Try to write as if you were there, then, in the voice and with the gaze of that age.

- On the bottom at the back of the page, write the year of your birth. Do not write your name!

\subsubsection{Reading (45 Minutes)}

- Chose one in the group to read all the stories (if many participants, two persons can take turns). Number the stories, as you go along, write the number on the top of the paper.

- Chose one to take notes, but be sure to make notes yourself.

- When reading the stories, the author shall NOT make herself known. Do NOT show in any way that it is your story that is read. And DO NOT try to help out if the reader have problem reading your handwriting. No one shall own the (correct) interpretation! The purpose is to get all kinds of interpretation on the table. So do not ruin the work by letting yourself be known as the storywriter!!!

- Read one story, slowly.

- Read the same story again, but read I as the other gender, that is she/he instead of I.

- What happens with the story when it's given the wrong gender? What makes it wrong? What is there to learn from such an exercise? 
- All the participants take notes. But you do not get into a full discussion and analysis of each story-except for the gender issue. It will have to wait until all stories have been read.

\subsection{The Setting}

Since we were 30 in the group and only 3 men, certain adaptions had to be made to make it work. And adaptions, in relation to the amount of participants and their gender, the amount of time at one's disposal and theme for the workshop, is part and parcel of the approach as such. Like other qualitative approaches, it always has to be developed so as to fit the purpose. What we had to do here was first of all to treat the stories as if they were all written by women so as not to make the male authors known. It further meant that there was no point in trying to guess the gender of the story. If the group had been mixed however, it would have made it an extra opportunity to discuss gender interpretations. It is also worth noting that the participants were asked to write the story in first person, not in the third person as suggested by Haug. This is due to my experiences from other short-termed workshops, where I have found that the participants find it easier to start writing if they can use the form of first person. Once a story is written, a new story in the form of third person, is however more feasible and accordingly an option for extended workshops running over several days.

We all wrote the stories-including myself-directly after my presentation, in the plenary session, so as to not make an interruption and a delay that might trigger a resistance. But also so as to de-dramatize the writing process and have it illustrated that it can be done anywhere and everywhere. Writing in a big group is also helpful in the sense that the act of writing of the others triggers your own writing. The atmosphere of silence and concentration when everybody is writing — and not for exams! - is also an expression of a particular kind of fellowship rarely experienced in academic settings. It feels good, as several participants expressed it when briefly commenting on the act of writing as they handed over their stories. There was also a general expression that it had been much easier and more interesting to write than they had expected when being presented to the topic.

The amount of participants however made certain arrangements necessary. If only a small group, the stories can more easily be distributed and read by each participant. Use of a laptop also allows for writing the story in three versions, just exchanging the I for a he and a she, thereby facilitating reading the stories in different gender versions. Since this was not an option here-only a few of the participants brought their own laptop-we split up into three groups with 9 - 10 person in each. In the groups the stories were read out loud by one person in the group, while the others listened and took notes. Each story was read out twice, the second time in the male voice telling the story. Commenting upon each story was not encouraged, due to the shortage of time, besides very brief comments as to the gender aspect of the text when given the "wrong" gender. The act of having the stories read out loud by one person —instead of having them passed around and reading them our selves—was experienced as a bonus. One could concentrate on listening and one would not have to feel a pressure to read fast so as not to have the next in line waiting for the story in question.

When all of us gathered again, in a plenary session, the analyzing process started. We opened for discussion by asking for spontaneous reactions to all the stories read in each group while I made notes on the blackboard. I then asked for comments regarding the exercise of changing the gender of the stories. Here we seemed to have had similar reflections in the different groups, including the one I took part in. The stories either seemed to be gender-neutral, due to gender playing a less prominent role when being a kid and relating to grown-ups? Or, we did not agree with each other as to the gender stereotyping, regarding activity, emotions or reflectivity expressed in the story. For some of us, this might be true of older generations but not of the younger ones, for example not true for our own kids. An important conclusion to be drawn from an exercise like this is that it is our own preconceptions or prejudices that come to the surface, not the actual and empirical founded gender patterns. As such though, the exercise is extremely valuable as a foundation for further explorations but one should take care to never make the mistake of using it as empirical evidence regarding gender patterns.

After having discussed the stories in more general terms, each group was to pick out one of its stories to be read and discussed in the plenary session. Three stories were accordingly chosen and here we allowed for comments and reflections after each of the stories had been read out loud. The analysis of these stories confirmed the issues raised in our previous discussions. So what were then at stake in these stories?

Before focusing on the content of the stories, there is one important issue regarding levels of analysis, that the stories made us particular aware of that needs to be mentioned. The instructions were to try to write the story in the voice of the child entering the scene in question. But of course, our voice of today as grown-ups and aca- 
demics is also always there, more or less visible. In addition to these two voices, we have the voice and gaze of us as readers (including the writer) when understanding the situation from our present knowledge and perspectives. When for example interpreting a story of a mother working full-time as a housewife, as a sad story, it's most likely (also) our present gaze that is allowed to illuminate the picture in this way. These different levels of analysis are of course not exceptional to memory work, it's just that memory stories make the process of reconstruction of experiences - orally or textually — more visible and obvious. It is accordingly something we also have to bear in mind when analyzing empirical statements and data. When the time was up for such meta-analyzing as well as the analyzing of the content of stories and the workshop had to come to an end, I asked the permission to have a copy of their stories for further analysis and potential publication. When that was granted, some of the participants wanted their story back, while others didn't. But let us now, finally turn to the stories!

\subsection{The Stories}

\subsubsection{Anna's Mother}

"I am really enjoying playing with Anna in her big bedroom. We always play the same game: we have collected lots of matchboxes and there are small imaginary people living in them. But they are so real to me as I kit onto the matchboxes with blankets and other household things that people might need. I am so engrossed in our game when Anna's mother comes in without knocking on the door. I have a small man in my hand and I feel really silly as I hurry to put him away in his matchbox.

She is looking at me and smiling. She looks really old and wears old-fashioned clothes. She is so much older than my mum. She has no chin so it looks as if her head is attached directly on her body. She offers us milk and we know we have to accept it. I don't like her milk as it is very creamy and not what I am used to. I think it must be good for me, as Anna's mum doesn't go to work. All her work is at home looking after Anna's dad who is also very old. I think she must know that the milk is good for me as her job is being a mum. My mum works and our milk is nor creamy.

I take the milk and drink it, as I want her to leave so that I can play again. She watches us drink but she doesn't talk, she never talks much. In Anna's house they don’t talk much as Anna's dad does not like noise. I am glad she does not ask about the game. She leaves and we play."

This story expresses many of the issues raised also in all the other stories:

- The comparison of mothers, one's own mother to the mother of the friend.

o Looks, clothes and food but also ways of being are used to pin down the differences between mothers. And it is this difference, very often perceived as strange either in a exciting or threatening way, that colors the picture of the friend's mother. As such it tells us something about the normative mother, that is, one's own mother. Here is an extract from another story, the story of Lynn to illustrate the point.

\subsubsection{Lynn}

“...In walks her mum, Lynn. It’s like Marilyn Monroe’s walked in. She’s so cool! She has dyed hair, and everything! Wow! And I've never seen her without make up, or nail varnish or with scruffy clothes. She always wears gold jewelry and heeled shoes. And she smokes-but in a cool way... She doesn't seem hesitant, or shy-just, well, in control... My mum's pretty but not like Lynn. She doesn't wear make up every day, or nice clothes, and she is not slim. I don't even think she even owns high heels... Lynn is a hairdresser. She does my hair sometimes, and it makes me feel really special, like an angel has touched me. I think her magic rubs off on me a bit, just for a while".

- The competence of mothers. In quite a few stories including this one, the competence of mothers is made an issue. Sometimes because it is a competence one's own mother lacks, as suggested in this story, but sometimes just because it is so striking (for example baking particular cakes, sewing skills—as in the story of the Danish mother, presented below-washing the clothes of the football team on a weekly basis, and so forth).

- Mothers as intruders. Mothers come in, sometimes without knocking as in the case of Anna's mother presented above, to show hospitality and make you feel welcome, through food or "pleasant conversation". Or, as in some over stories, to find out what is going on, to control or discipline the game or the very friendship relation as such. The structure and the culture of the house, also frames or make the mother into an intruder. In some stories, the kids play and spend their time together in the very same room as the mother, the kitchen 
or the living room. And in a few stories the mother actually plays with the kids as well. Mother Barbara, illustrate the last point

\subsubsection{Barbara}

"I am sitting at the stairs of my friends house and deliberately touch the chime which hangs from the ceiling. You can reach it when you are sitting on the $5^{\text {th }}$ step from the top. While I touch the chime I get a feeling of excitement because I know exactly that my friends mum, Barbara, will come rushing-actually not rushing but acting as if she is rushing - out from the kitchen and with a deep voice like in one of the fairy tales she will say "who is that ringing the bells". I would start giggling. To me it feels as if this is our game. Just hers and mine. I would do it every time I was there. It was nearly more fun than playing with my friend... She is a roundish woman. When she cuddles me I feel the warmth of her body, which is wonderful. I like her very much ...”

The story of Laureen's mother is an illustration of the opposite.

\subsubsection{Laureen's Mother}

"Laureen said I could pop over for my lunch. Her mum will be in, which makes me feel nervous. Her mum shouts a lot and it gives me a headache. I knock awkwardly on the bottom half (the top half is open) of the door. It's cold in the shadows of the house and I can hear children crying. My friend's mum is shouting. I don't want to let myself in, in case her mum shouts at me or if I accidentally let one of the children out. That would be terrible... I can never understand how she's employed as a child-minder. The kids love her, but I have no idea why, she's terrifying. She shouts at me to come in and to be quick about it and make sure I lock the door after myself... There's lots of banging and screaming and crying. I wished I had stayed at school... Laureen offers me a bagel with cream cheese for my lunch. 'What's that?' I ask. I have never had a bagel or cream cheese before; we never have that sort of food in my house. Laureen's mum shouts, laughing, 'You've never had a bagel?!' I feel stupid. I hate her, she's mean...”

- Mothers = home. In most of the stories the descriptions of the mothers are made into metaphors of the home in question, or the other way around. Not a single story illustrates a discrepancy between the image of the mother and the home. The home making role of the mother, is an expectation illustrated in the stories. The other way around, the role of the home in mother making, is an issue not raised in the stories but raised in our interpretations through present perspectives and knowledge. Here is a story that opened to such interpretations;

"I am sitting at the kitchen table in my friends house, having finally found a chair without a pile of magazines or a group of objects on top. Just behind my back by the windows were the birdcages maybe six, stacked on top of each other. Birds constantly moving, making noise. It was a sunny day, wings flapping, dust moving. The room was full. Various items in odd places, piles, stacks, collections of things; somehow in waiting. My friend's house was almost identical to mine in design. We lived in a modern housing development, but it was so different, we barely had enough furniture to fill the house, half empty bookcases and some empty cupboards. My friend's house had too much furniture.

My friend's mother had auburn hair and brown eyes, and was often dressed in velvet. Her movement was slow, deliberate somehow. She felt unusual, somehow alien. The environment made me feel free in one way but also unsettled."

- Mothers as positioners. The mothers, as grown-ups, have the power to position the child visiting her or his friend. The mothers ignore them or make them feel special, make them feel welcome or make them feel like intruders. And they treat them as children or as grown-ups.

“... I remember one time when I went to my friend's house after school and her mummy is in the kitchen making a cake-she used to make cakes all the time for people and sometimes they were rude cakes. I walked into the kitchen and she showed me a cake she had made with a couple on top having sex in a bed made of icing, in a cartoonish style and she was laughing loudly about it. I was a bit shocked at first-I was not used to talking about sex with my parents, but at the same time I felt a little bit liberated and a bit more grown-up-she was showing it to me as an adult, it felt, even though I was only a teenager.”

\subsection{From Motherhood to Childhood}

To investigate motherhood these stories are but a first step. From these stories a particular issue or situation can be chosen so to allow a focus and for more in-depth studies. New memory works can then be undertaken, indi- 
vidually or collectively, preferably combined with other qualitative approaches such as interviews, observations or analyses of texts, pictures and films. To me though, as a reader of all the texts-however varied the stories are and the atmosphere thereby expressed-I am left not primarily with an increased interest in the doings of motherhood, but actually with a (maybe) renewed interest in childhood. It is the gaze of the child, the vulnerability of her position as child that captures my interest as a reader of these stories, reminding of my own written stories about "other people's homes” (Widerberg, 2010). Just like in my own stories the stories of the workshop transmit tenderness towards us kids venturing out into the world where the homes of our friends represent some of the first steps to be taken.

Just listen to these three stories;

A.

"The story happened when I was about 11 - 12 years old. My mom went on a business trip and we lived alone with my dad for about a week. One day I had a doctor appointment that required me to travel to a different part of town, which I didn't know very well. My dad went to work early, I didn't need to be at school before noon, so I could go and see the doctor. I don't remember well what happened exactly, but I think I forgot the key at home so I locked myself out. And I also forgot the money that my dad left for me, so I could use them to pay for the bus fare. I discovered all this when I was already on my way to the bus stop, so I was standing by the middle of the road a bit lost.

I figured I was near my friend's place and I thought that maybe I can use her phone to call my dad or just stay at her place until school. When I called in, unfortunately, her mother opened the door. I wasn't prepared to tell an adult about my failure. But she looked so nice and she asked me what had happened. I only wanted to ask if her daughter was in, but I didn't notice how I actually told her everything. She looked grand, smiley, dark, short hair. She didn't look as somebody who could blame me. She and my friend looked alike.

'Oh, maybe you need some money?! I don't have much cash, but it might be enough for a bus'. I couldn't believe my luck. I was so happy and grateful to her. I thought she was the kindest person I ever met and my friend had certainly a mother one could dream of. I took the money and run to the bus stop. I returned the money through my friend the next day."

B.

“...I must have seen Inge's mother before, probably quite often, collecting Inge from school or at church but until that day she was fixed in my mind as 'tall and Danish', nothing more. Apart from being tall and very slim I can't remember what she looked like at all. But what I mainly remember from the visit to Inge's house was that she behaved quite differently towards me than mothers of other friends, because she had organized activities for the afternoon. First, we made some stuffed toys out of felt. My toy was a frog. We cut out two pieces of felt in the shape of the animal we were going to make and then sewed the pieces together, leaving a little space for the stuffing to go in. In my mind I was already terrible at craft generally and sewing in particular (my parents were preparing me to be an intellectual) and Inge's mother had to help me a lot with this task. Inge herself was good at sewing and happy to be able to make her animal on her own. I don't think I would have been an enthusiastic participant in this activity, or even particularly polite, but Inge's mother was patient and encouraging — and this was also very different from other mothers (including my own) who found their children's incompetence exasperating.

After we had sewn and stuffed our animals we could choose decorations; button eyes, sequins, pieces of ribbon. This was enjoyable in theory but frustrating in practice- these things are difficult to sew on and the effect was not as pleasing as I would have wished. My own mother would have seen this as confirmation that I was 'handless' (a word she used about me a lot to mean clumsy—-I don't hear it much nowadays) and lacking in artistic skills. Inge's mother was appreciative and impressed by the creation.

I never went to Inge's house again. Perhaps Inge's mother found it a more trying experience than she had let on. But I remained fascinated by how different Danish mothers are.”

C.

"I did not ring the bell. I'm told not to, just to step inside the front door. I hang up my clothes and I can hear voices coming from the kitchen. A subtle mumble. It’s Maria and her mother talking. I stand quite still trying to listen but I can't hear what they are saying. But to me it sounds intimate and cozy. After a couple of minutes I make some noise and enter the kitchen. Maria' mother gets up from the table, they have been drinking coffee and I have disrupted them. I feel like an intruder because they stopped their conversation. I was not invited to sit down with them, which I would have liked. And Maria’s mother smiles briskly with a put on cheeriness, saying, 
'So, here you are. All well?' Not waiting for an answer. I do not feel she takes an interest in me and not only that, I actually feel that she doesn't like me. Due to that I try to make her like me but feel that that only makes her dislike me even more. It's as if she can see the true me.

I never asked her or my friend about it and now they are both dead.”

Stories like these touch us and linger in our mind, making us look upon children, our own and others, and maybe in particular the friends of our kids, in a new way. Ending up with a new thematic focus is not rare when using memory work. In fact, the very purpose of the approach is to make us discover things we take for granted. Like kids.

\section{From Memory Work to Experience Stories}

Most of my courses on memory work, have however lasted 3-days, which make other variations to both procedures and themes possible. The theme, for example, can then be discussed and decided collectively. But since the participants most often will constitute a temporary group and do not know each other beforehand, no sensitive topic should be chosen. Besides suggesting firmly that the group should choose a "dull", everyday topic to test whether the method can bring new knowledge to the things we take for granted, I do not interfere in this process. What topics have the groups then chosen? They include topics such as anger, blushing/sweating, knowing/not knowing something, vacuum-cleaning, dancing, getting dressed, and, travelling to work.

Once the topic has been chosen, I ask the group to write what has really happened, yesterday or long ago and use similar instructions to those used in the case above. But here we also have time to let the participants write and analyze the story in three versions: in first person and in male and female third person. With today's laptops, this is easily done. One simply writes one story and then use a replace order, for example, to exchange "I" with a "she" and then the "she" with a "he". Even though the language might become a bit odd, three versions of the story are thus easily made. One purpose is to see what happens when you objectify yourself (sometimes it is easier to write a story in the third person) or establishes a distance to yourself. More importantly, by using the male and female forms, the gender of the text is made visible, often in ways not visible when the gender was "accurate". Just like in the above-presented case the text is written then and there, usually within a time limit of $1 / 2$ - 1 hour. De-dramatizing writing by doing it together, in a limited time and anonymously, makes it seem less pretentious and scary. It is my experience that under such conditions, everybody can write something.

After the stories have been written and prepared in three versions for all participants, we read the stories together. We then discuss and analyze them as a whole. What kinds of situations and of what life-periods have we written about? And what have we not written about? Sometimes the silence in what we choose not to write about is just as interesting and thus worth analyzing, as what we did write about. For example, on the theme "to know/ not to know something", none of the 20 participants wrote about academic knowledge, although they were all students. Instead, knowing was here taken to mean being able to undertake and master, especially, bodily tasks in childhood or in youth. In the discussion, they all expressed insecurity in relation to knowing in academe as the probable cause.

In this first and more general discussion and analysis of all the texts, the gender aspect, made visible through the three versions she, he, and I, is also made a topic. What makes the gender appear correct or wrong? Is it the acting or the wording? For example, on the theme "Getting dressed", which gender-when naked —starts by putting on the socks? And why do women always put on the underpants first, and not the bra? How we do gender all the time is here made quite clear. But it also illuminates how very gendered our way of wording and writing about something is.

To be able to make a more in-depth analysis of a situation and its language, one or two stories, usually rich ones, are chosen. Everything we see and learn when analyzing the chosen story is written down on the blackboard, first unsystematically and later organized into sub-themes, situations, relations, emotions and so forth. Analysis goes on until nothing new comes up.

Summing up my experiences from the 3-day courses described here, I find it extremely well suited for grasping experiences. A major reason is that the topic for the writing is always a specific situation or an event on a theme. Writing about anger for example, means writing about a specific situation in which I was angry. When this is used collectively, it is the situation rather than myself that is in focus. It is here a method where the main thing is not the I, but rather the situation — the relations in the situation - that make up the experience. This facilitates an interpretation of social relations that form the experience, rather than looking for the causes in the in- 
dividual. Memories are here written and interpreted to see the social relations, on all levels, that shape the experience in question. It is precisely this aspect of making the social aspect of the experience visible that makes the method particularly fruitful. It can indeed be used to unveil the things we take for granted in everyday life—not least gender!

The enthusiasm I had encountered when teaching the method and the intellectual thrill of it all, learning so much about the social, inspired me to try to develop it for use in regular teaching. I wanted to explore if and how I could use it when teaching regular classes in sociology on BA and MA-levels but of course also, and maybe especially, when teaching gender. The technique developed I've labeled "experience stories".

I here want to illustrate the method through a description of its use at a particular occasion that I have documented in writing (Widerberg, 1998). The way in which the stories were analyzed and what they could tell us about the theme, as well as the students' reactions, will be highlighted.

\section{"Describe (Concretely!) a Situation-Today, Yesterday or in the Near Past-When You Felt/Experienced/Was Made Aware of Being a Woman/Man"}

It's 28 February 1996. I'm scheduled for two lectures for second term undergraduates in sociology on "Gender Perspectives in/on Sociology". I introduce myself and tell them, about one hundred students, that before I start my lecture, I would like them to write a couple of lines on the titled theme. I tell them to write no name on the paper, but just to indicate their sex. I also tell them that I will have read all the stories by the next lecture when I'll discuss with them my analyzes of their material. Papers are then handed out and the students are given 10 minutes for the task. After some initial laughter and bodily restlessness, they all settle down to write. When time is up, I ask them to hand in the texts, and the way they hand them over shows that they have enjoyed the task and are looking forward to learning more about what this is all about. They'll have to wait until next time, I tell them, and then proceed with my lecture.

Ninety-one (91) stories are handed in, 60 by women and 31 by men. Two-thirds of our undergraduate students are women so the proportion of female and male texts corresponds to the actual gender ratio in the discipline. I read through all the female texts first and note the type of situation they wrote about. I get more than 30 different situations, such as:

Wasn't heard/seen, dressing, in relation to a man, talking about equality/gender, flirting, cleaning up, "girls' talk", menstruation, chivalry, prejudice, doing gymnastics, in town at night (frightened), the Ladies-line, work-tasks, I'm cooking, he's cooking, having the dishwasher installed, being talked to as a good girl, being silenced in the study-group, dancing, male computer-games, not coping with the machines (computer, copy-machine, and so forth), being more interested in the discipline (than men), men being unclean/unhygienic/not smartly dressed, getting a women's job, work division on a week-end in the country, feeling pregnant, ladies cloak-room, showing emotions.

Only two texts expressed no reflections on gender. The men's texts were just as varied. The situations they wrote about were:

Opening doors/paying for her beer, shaving, argument about washing up, reading about or discussing gender, complaints from the girlfriend, taking a pee, when women expect one to act/perform/know typical male things (replacing light bulbs, fixing the car, washing machine, etc.), being object of a woman's desire, men's talk/boys' talk, dirty talk, dildos, using the ladies room, didn't do housework, heard women talking about menstruation and birth-control, flirting, watching male sex-offenders on film (embarrassing for the male gender), watching men's films, talking with the son about the tough sex, women dominating in the study-group.

Like the women's texts, only two texts reported no reflections on gender. The men's texts, however, were shorter and it was unclear, in a couple of them, whether they meant to be joking or not. Taking a pee, for example, is that an effort to make fun of the task or is it a real answer? Some of the men's texts also expressed a sense of being provoked by women and equality themes. Similar expressions could not be found in the women's texts. Comparing the texts of the men and the women, it is however the similarities that maybe are the most striking. They both reflect on gender when:

-Doing traditional gender tasks

-"Doing", that is, dealing with their bodies (as sex or gender)

-Being together with their own sex

-Flirting 
-Discussing gender or equality

-Perceiving the other gender as dominating

Some men report reflecting on gender when listening to women talk about “women stuff”, while we don't find corresponding stories by the women. The women on the other hand, write about being talked to or treated as an object by the men but also by each other. Such experiences are absent in the men's stories. Another interesting difference is that women reflect on gender when men do traditional female task, whereas men do not think about gender when women do traditional male tasks.

Focusing on type of relations more than tasks, both men and women express reflecting on gender in;

-Relation to/being with their own sex

-Relation to/being with the other sex

-Being with the other sex when gender/equality is the theme

The men reported experiencing gender when acting. They don't report being treated as gender-objects in the same way as the women express in their stories. Both parties are embarrassed by their own gender and they both express a bad conscience regarding issues of equality. They don't do or feel what they "should” feel. They don't live up to the "equality standards” of either themselves or their sex. And they don't express any enjoyment or pride of their gender.

I asked the students after presenting these results; is that what gender is all about to you? Is gender only about equality issues? Do you accept the official equality discourse and value your own behavior and feelings in its light, to the extent and in the way you express it in these stories? Aren't you ever happy or content that you are a man or a woman and hasn't that got anything to do with equality? Or are you just writing here what you think is expected of you as a student in sociology? That is, are you writing about gender in the way you've learned about gender through sociology? What else could gender be about?

The questions were consciously formulated in a provocative way. I had myself been provoked by the negative and self-critical tone in the stories. Gender conceived as equality was obviously no fun at all; it only made them feel bad or wrong. But was this really true? The students listened in dead silence.

Class was over, the students crowded in the corridors, engaged in lively debates. Gender-their gender- and Sociology - their sociology — was the theme. It would have been a great starting-point for further explorations of our, their, and my understandings of gender and sociology. With more and other stories on specific and selected themes, this could have been interpreted by the students themselves, in groups. But my time was up. I had given them some tools and they had given themselves and me materials and themes to reflect upon.

Since then I have used this technique regularly and so often on all kinds of themes such as class, and emotions, that documenting it all is a project on its own, unfortunately yet to be done.

\section{From Teaching to Research}

As one thing leads to another, as illustrated above, so have my research topics and projects and it was actually here, in research, that my use and exploration of memory work started out triggering also my teaching practices. Since my use of the approach when doing research can be transformed into teaching and inspire to other kinds of teaching exercises than the ones I have presented above, I will here briefly present some of my research projects where memory work has played a decisive but varied role. And let me start with the use of the approach as an individual endeavor.

As an individual enterprise-in writing and in analyzing the stories - the variations and complexities guaranteed by the gaze of the others in memory work as a collective enterprise, is absent. And yet and to partly different purposes, which I will try to illustrate below, memory work as an individual enterprise can be quite fruitful.

\subsection{Sexual Harassment-A Pilot Study}

Embarking on a research project on sexual harassment in 1987, I was determined to try out the method of memory-work, one way or the other. I had just read Frigga Haug's book (Haug, 1987) and was struck by the insights and knowledge produced by their use of the method. It was evident that the new knowledge they presented was a result of a new way of knowing. For me then the question was' accordingly' not if to use the method, but how. With me on the project I had Harriet Holter - the grand old lady of Scandinavian women's research-and a group of enthusiastic female MA-students who were offered the opportunity to write their theses on the theme. None of the students knew each other or us beforehand and the issue of hierarchy had to be addressed. Harriet 
and I were not only much older but also belonged to another category-professors-while they were students. The idea of doing memory-work in this kind of group and on such a sensitive theme as sexual harassment encountered only embarrassment and silence when I raised the issue. Besides, the students said, they did not have the time it would take to do it "the Haug way" since they only had a year to work with the thesis. It was therefore decided that it was up to each participant to decide if she wanted to embark on an individual memory-work project but that the results - the insights won-should be shared within the group so as to benefit the project as a whole. In the end only two of us did a kind of memory work, while all of us did bits and pieces of it. The purpose of using the method was simply for all of us to prepare ourselves for the interviews that were to be done later in the larger study.

None of us could have imagined how decisive this work would be, not only for the form and content of the subsequent interviews, but also for the entire design of the project and our understanding of the phenomenon of sexual harassment. How did we go about this individual memory-work, and what did we learn?

The theme for my own memory-work was sexual assaults, including sexual harassment. Over the course of half a year I wrote down all the different occasions I could remember-as stories, written one at a time. I tried to focus on what I could remember, how I remembered it and how I interpreted the situation-at the time and today. I found:

1) I remembered occasions I had forgotten. All the events were not remembered at once, but came to the surface over a longer timespan, triggered by the memory-process as such.

2) The number of such occasions and their variations surprised me. Is that so, I wondered, for other women as well?

3) I had problems defining some of the events as assault, even though they were clearly unwanted from my part. The problem was the language, the wording, and the connotations of assault.

4) I experienced some of the events as assaults even though "nothing” actually happened-for example, a situation of intense threat.

5) I felt shame in relation to several of the events. I would not wish to tell anybody about them, even though I knew I was not to blame. If I had been interviewed I probably would only talk about the situations in which I did the "right things", not the ones when I was "naïve” or "stupid”, that is, situations in which I behaved as if there was no such thing as patriarchy.

6) The shame and contempt I felt towards myself as a victim. Didn't that indicate that I felt the same towards other women as victims? Feelings and thoughts I did not wish to have or to know began coming to the surface.

These insights, brought about by the memory-work, were discussed and confirmed in the research group. Although we did not read and analyze each other stories we did discuss our reflections and insights. And these collective discussions triggered new stories and further reflections and insights. These collective discussions accordingly had several consequences for the design of our research project on sexual harassment and for the interpretation process throughout the project (described in our book, Brantsæter \& Widerberg 1992, in Norwegian). First of all, we made follow-up interviews with victims into a standard procedure. The memory and reflection process, triggered by the first interview, was included and documented. Any changes in the stories between the first and the second interview were registered and understood as being the way these things work, rather than as proof of deviations or untrustworthy statements/subjects. The result was an understanding of sexual harassment as experiences that are both interpreted and continuously reinterpreted in relation to other/new experiences, age, and varying gender-experiences and gender-relations, etc. Therefore, it is impossible to state or measure the consequences of assaults of harassment once and for all, even though this is what most research seems to imply. Experiences of sexual harassment are not a separate phenomenon in a woman's life; they are part of her self-image, her image of others and the relation between others and herself. This is something you have lived and are still living with.

This memory-work on sexual harassment had consequences not only for the research project, but also personally for us, in the research group. The experiences that we remembered through the memory-work and the collective discussions changed our understanding of ourselves. We seemed to have lots of victim experiences, without having previously thought of ourselves as victims: we had no explicit victim identity. Maybe few of us actually have! Perhaps this identity is just as much a construction brought about by the traditional methods and approaches used within social sciences, where assaults are "phenomenized” instead of "relationized”, personally and culturally. In any case, for us and up till then, our personal identity project and cultural identity contribution obviously had been to construct an identity that made invisible any personal or structural victimization; invisible 
to ourselves, and to others.

To study how this was done, in detail, the memory-stories would make an excellent starting point for further memories, reflections and discussion. In other words, the memory-stories can make us question our own identity-story, as well as showing exactly how the identity both shaped and was shaped by the experience in question.

Memory-work led me to question the earlier implicit version of my life story and identity. More specifically, it made me question my sexual history. Having written about my memories of assault, I became curious about my memories of sexual pleasure. How did they relate-in time and place — to the assault memories? So I started on another memory-work, this time on sexuality, and another one later followed that, this time on knowledge-a natural and urgent theme for me as a feminist researcher.

\subsection{Sexuality and Knowledge-A Research Project}

For more than a year I wrote memory-stories on the two themes of sexuality and knowledge, in hopes of understanding myself and my social context better. At first I had no intention of publishing anything; when there were no more stories that I felt urged to write, I simply put them away. It was not until a year later, when I was on sabbatical and had time to read them all through, that I saw them as material for a book.

Sexuality and knowledge are both about being in touch: about pleasure, comfort, honesty, personal growth and fulfillment, and about being present. A wish and an effort that in reality often turns to the opposite: instead, we feel discomfort, distance, diminished personally, non-present, dishonest and oppressed. This happens both in the act of sexuality and in the act of knowledge. I saw all this when analyzing my own stories, but I also began to realize how gender links knowledge and sexuality together, connects them and sets them in motion. Knowledge, sexuality and gender are formed in the same process. In negotiations as to the kind of woman and man we want to position us as, knowledge and sexuality appear as important pieces of the bargain.

Seeing these patterns in the memory-material made me wonder whether this could be used to explore and discuss issues of female subjectivity and objectivity. More specifically, I wanted to explore the kinds of experiences that might explain the contents as well as the forms of feminist knowledge of production, i.e. the feminist endeavor in academe.

With this as my purpose I wrote the book "The gender of knowledge” (in Swedish and Norwegian, Widerberg, 1995), where I present and make use of the material from the memory-work on sexuality and knowledge. Since the stories had been written one at a time with the purpose to explore and illustrate diversities rather than similarities and connections, the result is of course a picture of an I that is multiple. This is accordingly a result of the method.

Summing up, I would accordingly like to stress that understandings of identity are formed not only by our theoretical approaches but also, although less acknowledged, by the very methods we use. Exploring methods accordingly implies exploring the social and the other way around. Different understandings of the I and the social will require different methods. Identity, theoretically understood as multiple I's, requires empirical methods that can contribute to the unfolding of the I into a variety, also in terms of voices. Here I have tried to argue that memory-work can be used as such a method. As such it can contribute to a fruitful challenge of the genre of auto/biography where a person tells or writes her story along implicit guidelines for a story of that kind (sequencing, coherence, a beginning and an end, the construction of an I, etc.). As an individual enterprise the researcher can let the stories and analysis expand in all the directions she herself finds most fruitful. But it is not until her work is read and commented by others that she will learn of other possible interpretations and experiences. As a collective enterprise this is guaranteed from the very start, by the stories and gaze of the others.

\subsection{Doing Body/Texts: Memory-Work as a Collective Research Enterprise}

Early in the autumn of 1995, Drude von der Fehr (whose field is literature), Halldis Leira (psychology), Ulla-Britt Lilleaas (sociology) and I (sociology) met to discuss the possibility of working together on a new research project. We had all worked together previously in different constellations, and we knew of each other's research projects and approaches to knowledge. Just how well, though, varied, as did how well we knew each other personally. What we all shared, however, was a wish to work with the theme body/experience in a way and in a connection that could enable us to learn something new. The connection was clear from the start: we wanted to work together within an interdisciplinary dialogue where our disciplinary understandings could be challenged and expanded. The trigger in this process was to be the theme-the body/experience, a challenge to 
any disciplinary approach. In understanding body/experience, we aimed to use our academic disciplines as best as we could to see how far that would take us. Only then could the limits of our different disciplines become visible and we would find out what we each had to offer and what actually might fall in-between or even outside disciplines as ours. Disciplinary approaches were accordingly to be used when investigating the body/experience. On the other hand, we didn't want these to restrict us in our search for new understandings. Of course, we also knew it would be unrealistic to try to turn off the disciplines in our way of working and thinking. They have by now become an integral part of us, whether we want it or not. But we wanted to widen our gaze, follow our curiosity and be open to the unexpected. To achieve this, we knew we would have to develop and make use of other ways of working than the ones we had grown accustomed to within our disciplines.

The wish to work in another way and using other kinds of methods and approaches was very much connected with the theme we had chosen for study. Although during the last decade the body had been the theme within the humanities and the social sciences, particularly its feminist branches, we still wanted texts that problematized and made the body visible as lived experience, and the other way around, that is, as embodied experience. There were of course one or two single and exceptional contributions, like the works of Frigga Haug, or in particular fields-like sexualized violence - but they had failed to leave any major traces in the dominant intellectual discussions "on" the body. We suspected that disciplinary thinking might be the culprit here; at any rate, it had not contributed the kind of knowledge we sought. Obviously we would have to proceed in another way.

Some of us had previously worked with alternative approaches to become aware of and to express, bodily or in writing, body/experience. We had tried them out and used them in exercises and workshops. As these had been very positive experiences, we now decided to make use of similar ways of working in our research group. At our very first meeting, we decided that we would do bodily exercises and then write them down as texts. It would be these texts and not the theoretical or meta-theoretical body-texts of our disciplines that would then form the material to be discussed in our interdisciplinary dialogue.

The approach: Over the course of two years, we did four different thematic exercises, some of which we did more than once or on similar themes, and wrote them all down as texts. The themes for these exercises were as follows: "having a good day", "a day of turning", "a day of low energy", and "a day of "where am I in the body?"” in that order. Finally, we also wrote our "body biographies”. The first exercises, "Having a good day" and "A day of turning", involved trying to obtain pleasurable situations or turn non-pleasurable situations or work-tasks into pleasant ones for an entire day. Then we wrote a text where we related what we had done and experienced but also what it all, including the writing, made us reflect upon. "A day of low energy" involved trying to use less energy, that is, to decrease our level of energy for a whole day. As in the previous exercise, this was to be an ordinary day; we were just to do the day differently. "A day of 'where am I in the body?'” was an effort to try to feel and register which parts or areas of the body made themselves known to us throughout a whole day. "Body biography", finally, was an attempt to write an autobiography, taking the body as the starting point; what the body had been or meant to us and how we had lived, experienced and inhabited the body.

The themes for the exercises, the way we enacted them as well as the way we discussed and analyzed the texts evolved and varied throughout the process. We have searched for the most fruitful way of working and have taken the path that our desire for knowledge and its intoxication has led us. It has been work filled with pleasure and desire, not always easy and often both sensitive and conflict generating. It was work we did in addition to our ordinary research and work tasks, in the evenings and at weekends. Our project—-titled "The Body between Theory and Practice" - has been our "priceless pearl": we have guarded it, tended it and enjoyed its radiance. From our meetings, to which we sometimes staggered, dead tired after a whole day at work, we have returned enlivened, energetic and excited. We believe that nursing the desire as we have done, in relation to themes as well as how our applications in exercises and texts, has been the precondition for the development of knowledge we have experienced throughout the project. For us, desire has not only been a driving force but also a tool to develop knowledge.

Here I will summarize our way of working in an idealized model, to inspire readers to try it out on other topics as well. Our way of working developed underway, so the description below cannot give a full or true picture of how we actually went about things. It should not be read and used as a set of rules, but rather as a set of guidelines to explore and develop the method further. In brief, then, our model can be summarized as follows:

1) The theme for the exercise was chosen collectively. We also decided on a particular day or time of day for the exercise. Knowing that all of us, separately in our different situations, would be doing the exercise we had decided upon was both comforting and stimulating. If, however, one of us forgot to do the exercise on the cho- 
sen day — this happened more than once—she picked out another day for herself.

2) The exercise was written down as text. Our only guideline here was that it shouldn't be too long. Each of us could write in the form and kind of language that seemed most fruitful. Inspired by memory-work, we all tried to be as descriptive as possible. An interesting question for us when analyzing the texts and for the reader of our texts and chapters in the report (Widerberg et al., 2001) is whether the discipline makes itself known, and in that case, how this is done. To us, it was an attempt to de-emphasize our disciplines at this stage in the process. Later on, in analyzing our texts, however, we very consciously made use of our disciplines.

3) The texts were sent out to the others in the group and the group met to discuss them. We discussed the texts both separately and all taken together. These discussions were seen as preliminary. There was so much content in each text and so many angles and approaches to be taken when interpreting it that we could not hope to cover all in this first round. It became quite clear to us, early on, that each one of us would also have to work extensively with the analysis on our own (Widerberg, 2001a, 2001b). This was also the guarantee for a fruitful interdisciplinary dialogue.

In relation to traditional memory-work, memory-work á la Haug, there are some important differences affecting possibilities for analyzes and arguments and knowledge being produced. First of all the stories were written about the immediate past-except for the body-biography — and not about what we usually conceive of as memories. Secondly, the story was sometimes of a situation but sometimes of the happenings of a whole day. This of course affects the descriptive character of the text. Besides, no instructions were given as to how to write the text, except a recommendation to be as descriptive as possible to obtain thick descriptions. In this aspect the stories greatly varied. Other variations occurred among us and in relation to the topic of the exercise. Thirdly, the stories were not written or analyzed anonymously, since the very aim was to investigate our disciplinary differences in writing, reading and analyzing. Finally, based on our individual stories and collective discussions and analyzes, we each wrote a kind of body-biography. Here we made use of the genre of biography but on a specific theme (the body). The insights won through the body project (exercises made and texts written and analyzed) played a decisive role in what was highlighted and how in the biographies. A hybrid method accordingly grew out of our explorations.

Working in an interdisciplinary way meant trying to see what we could learn from each other's way of proceeding, as well as trying to clarify, explore and even strengthen our disciplinary traditions. The fact that we were using an approach that none of us could claim to be experts in - it was in fact new to us all-made this easier, not to mention the fact that we respected, trusted and liked each other. We were the project, it was for us, and it was ours.

\subsection{The Sociality of Tiredness}

The tiredness that surfaced as a topic in the Body/Texts project (presented above) caught my interest. Ulla-Britt Lilleaas and I decided to embark on a new research project where we would investigate it in depth, sociologically. In this research project titled "The Sociality of Tiredness—on the Handling of Tiredness in a Class, Gender and Generation perspective,” we made use of a whole variety of memory-work inspired methods and techniques. Taken together, they made possible the kind of knowledge produced and presented in the book "The Times of Tiredness" (in Norwegian, Lilleaas \& Widerberg, 2001). What then did we do and what did that make us see?

To start with, different memory-work inspired pilot studies were undertaken to inform and enlighten the design and approaches of the empirical—quantitative as well as qualitative-research we had planned. These were writing pictures of tiredness from childhood, family and friends, family portraits of tiredness and a diary on tiredness.

Pictures of tiredness from childhood, family and friends. Instead of writing about particular situations relating to tiredness, we wrote stories that aimed at giving a picture of how tiredness was expressed and handled in the families in which we grew up. What memories and pictures did we have of our parents and sisters and brothers in relation to tiredness? The stories we wrote raised a variety of issues we then pursued in the subsequent empirical investigations, such as for example;

- The family history of tiredness and its inheritance and gender differences in how tiredness is expressed and handled.

- The language, time and space for tiredness (what, where and when can different types of tiredness be expressed?). 
Family portraits of tiredness were accordingly made a theme. Our written pictures of tiredness within the families we grew up in and the friends we were surrounded by made us curious as to how it was perceived by the other members of the family. To find it out, we decided to interview them as well as our partners and children. In the interviews with our parents we started out with questions as to how they perceived themselves in relation to tiredness. Were they the tired type? How had they handled tiredness at different stages in life? And what about their own parents, how was tiredness expressed and handled by their parents when they grew up? In the interviews with our sisters and brothers we added the focus of their work situations. In the interviews with our own children the work situation was of course exchanged for the school situation.

Besides confirming the relevance of the themes, presented above and brought up by our writings of pictures of tiredness, the issue of tiredness at work rose as an iceberg in the dark. It seemed to be a most complex issue that needs to be pursued in detail so as to bring forth knowledge of how the causes, expressions and "mastering" of tiredness are determined structurally and culturally. Other issues also rose to the surface, such as;

- Tiredness trauma. Does it make sense to talk of such a thing? For example if one has lived through a period with little sleep and rest, can we talk about it lingering on as an embodied memory affecting future habits in relation to tiredness, sleep and rest?

- Worry of tiredness. Worrying of becoming tired seemed to be tiring in itself, sometimes even more so than the actual tiredness one felt when the worrying was finally all over.

- Tired persons. Asking about tired persons among friends or in the family seemed a fruitful way to get information about how they perceived themselves as well as value judgments relating to tiredness.

To further investigate all the types of tiredness we had spotted through the pilot studies described above, we decided to write a diary focusing on tiredness. We were, at the end of each day or early next morning, to write about that day in a tiredness perspective. What had made us feel tired, where was the tiredness bodily situated and how did we deal with it? For a whole month, we kept this diary, learning not just a whole lot about ourselves but more importantly how we had to proceed in the forthcoming interviews. The diaries seemed to indicate that tiredness is about everything, one's whole life and way of relating. To phenomenize, that is, making it into a phenomenon that can be studied isolated on its own is therefore problematic and wrong in more than one sense. On the other hand, it is only by focusing on tiredness, trying to specify it, that it is taken for grantedness is dismantled and problematized. Some of the things I saw in my own diary that I intended to pursue as issues in the interviews were for example:

- "Just finish-up type". Working intensively so as to have time to relax when it is all done. But when is work ever all done? And for whom? Women's work is typically never ending, neither at work nor at home. So when can women rest if they are the "just finish-up type"?

- Experiencing giving in to tiredness as something sinful. Wasting time, making use of time and other such internalized cultural understandings might be hard to get rid of if they have been embodied as habits and parts of our identity. We are, in short, maybe not the kind of persons who "waste time".

- Getting tired by, in and of social relations. How do we handle it when our role, professional and/or gender, is threatened? When we cannot be the kind of person we should or would like to be?

Summing up, the extensive pilot projects described above had a profound impact on the design of the subsequent empirical investigations. Not only the themes chosen but also the very approach of and in the interviews were colored by what we had learned through the pilot studies. To be thoroughly descriptive, so as to avoid taken for granted statements and pave the way to substantiated variations, was a first step. The overriding question "how is tiredness done" was in the interview operationalized to questions about "what generates and what steals energy" during the day. We tried to trace our interview persons through their different work situations at home and at work, during the weekday and the weekend. We made them explain their different work-tasks in detail, from morning till night. We also made them reflect upon the different types of tiredness and where these were bodily situated and how they were handled. Some of them even wrote tiredness diaries for a week, as an option upon our suggestion, and had them sent in. Although tiredness is a favorite daily topic, especially among women and the younger generations, this was the first time, so they said, that tiredness was the subject of serious reflection and investigation.

Making use of one's own memories, experiences and pictures when designing and doing research has at least one more merit that finally is worth mentioning. Becoming aware of one's own experiences on the theme makes it easier to be more genuinely interested in the research subjects as "the others" since there is less need to use them to find out about oneself. Equally important, one knows what it is like to be subject to investigation on the 
topic chosen. All this of course also informs both design and approach, which I have tried to illustrate above, maybe however most clearly when presenting the memory-work on sexual harassment.

As for teaching finally, the use of memory work in the research projects here presented can easily be transformed into teaching, either in regular classes or as themes for courses or homework and essays on all levels and on all themes. I have for example had MA-course students write about the tiredness of their family in a gender and generation perspective, relating their history to the concepts and understandings presented in the course curricula. And I always propose the MA- and PhD-students that I supervise to do a memory work inspired pilot-project on their theme at the very start in their research process. Just like in research the approach always needs to be accommodated so as to fit the teaching occasion, group and theme. Quite often a more theoretical background regarding memory and knowledge then needs to be lined out, so as to state the link between the subjective and the inter-subjective, the personal and the social and political. Following reflections can then be used as such a foundation before embarking on memory work or experience stories.

\section{Remembrance, Memory and Memory Work}

\subsection{Memories We Live by}

In most cultures remembrance is cultivated both individually and collectively. In families we tell and retell family memories to knit us together, to help us negotiate and shape the aims and functioning of our family unit (Smart, 2011). And we are surrounded by institutions that tell and retell the memories of the community, with a similar aim: to knit us together, to make us participate in the well functioning of our society. Films, books and art, but also urban and rural planning, are created to make us remember, not only our own history but also the histories of other generations and groups. Memories and remembering are accordingly about identity—about who we are as individuals, as a family and as a society- and as such, of course, they constitute a highly contested area. We know that experiences and memories of oppression, violence and sexual assaults are made to be forgotten in the family as well as in society. The issue of whose memories and what kind of memories should be highlighted is therefore a battleground in both research and politics. Embracing memories as a means to discuss continuity and change of and within the family institution is therefore asking for trouble. The fact that the tool, the memory, is a construction and as such a subject for social investigation in its own right before being made use of as a means to investigate continuity and social change, does not make the task any easier. In this article I have argued that there are ways of working with memories - using memory work as an example that presents an alternative to the narrative turn and its dilemmas, producing not only other memories but maybe also other outlines of individual and collective identities.

\subsection{Memories We Tell}

Within social science research memories are used to substantiate an experience (or set of experiences), to pin it down descriptively so as to make the retold experience as contextually rich as possible. The aim is to make us all—research subject, researcher and reader-to engage with the experience anew. Memories are "collected" or "gathered" on specific themes or as a part of a life-story/(auto-) biography, through interviews, written texts, diaries and documents in which visual means (photo, film) too may serve as triggers. And each theme and approach has its own challenges and merits regarding knowledge claims. Yet there are of course also some challenges that are shared, affecting knowledge claims that not only call for our attention but also for the exploration of other approaches, such as memory work.

As Freeman (1993) has pointed out, we live our lives in episodes. The overall plot of the life history that makes up of all these episodes is something we cannot know until afterwards. Remembering is therefore not only a recounting of the past, but also a reinterpretation. It is an interpretative act that aims to expand our understanding of the I. Through memory, a new relation between the past and the present is created, one that can give structure to past and present experiences. Memories from the past are therefore not memories of facts, but memories of how we imagine and construct facts.

Further, what we remember is dependent on language and on culture. Now that we are adults, language plays such a decisive part in the formation of an experience that we find it hard to remember anything from our preverbal childhood. Language thus both enlightens and darkens an experience. Culture, on the other hand, is decisive to what is considered important and accordingly what we remember. That is why what is remembered will 
vary with culture and historical period. People from different cultures who share the "same" experience may well remember it quite differently. The same is true for different groups within a culture. Oppressed groups, for example, often do not want to or even cannot remember. This has been interpreted (Taylor, 1993) as an expression of resistance towards the submission or oppression pervading their experiences and their memories of these. In order to survive and regain dignity they learn to forget. And if, and when, they do remember, the unbearable makes the memories incoherent and fragmentary. This unwillingness to remember and the way one remembers if forced to, is highlighted in the literature on sexual assault, for example.

To remember, finally, especially in writing, is not only to gain something — for better and for worse. It is also to lose something. Once the memories are written down, it is hard to remember anything but what has been written. Likewise, what we tend to recall of visual impressions of childhood is very much determined by the photos in the family album. In a way, the text or picture locks or fixes the memory, and thereby perhaps also future experiences_-registered, reflected and remembered in the light of what we have of memories of our past.

These brief comments on some aspects of the memory process constitute, I believe, an argument for developing methods to unfold memories other than those that culture compels us to tell and also to live by. Memory work is such an approach to be used and developed in research and teaching so as to fit the occasion, subjects and theme.

\section{Concluding Remarks}

Memory work is an approach developed to help us problematize the things we take for granted and as such an invitation to methodological explorations in teaching and research. By our own stories of memories and experiences we are invited to look for variety-in our own stories as well as in relation to the stories of the others-regarding content as well as interpretations. A set of techniques is developed to make this happen, in writing as well as in analyzing. Focusing on the social aspects of a story does not only imply a possibility to connect different analytical levels (micro and macro) and verify concepts and theories. It also allows us to question or specify fixed or simplified categories and concepts by making other memories, experiences and understandings visible. As such it is an approach that stimulates creativity and knowledge production in both teaching and research, to the joy of all participants. I have here tried to illustrate how it can be used and what kind of knowledge that can be gained. Hopefully these illustrations can inspire further use and development of the approach. There is so much left to discover and so many ways to develop the approach so as to suit the occasion. A dream situation for us all: student and teacher, researcher and research subject!

\section{References}

Brantsæter, M., \& Widerberg, K. (Eds.) (1992). Sex i arbeid(et). [Sex at Work.] Oslo: Tiden forlag. (In Norwegian)

Freeman, M. (1993). Rewriting the Self. History, Memory, Narrative. London: Routledge.

Haug, F. (Ed.) (1987). Female Sexualization: A Collective Work of Memory. London: Verso.

Kaufman, J., Ewing, M. S., Montgomery, D., \& Hyle, A. (Eds.) (2008). Dissecting the Mundane: International Perspectives on Memory-Work. Lanham: University Press of America, Inc.

Lilleaas, U.-B., \& Widerberg, K. (2001). Trøtthetens tid. [The Times of Tiredness.] Oslo: Pax Forlag. (In Norwegian)

Smart, C. (2011). Families, Secrets and Memories. Sociology, 45, 539-553. http://dx.doi.org/10.1177/0038038511406585

Taylor, C. A. (1993). Positioning Subjects and Objects: Agency, Narration, Relationality. Hypatia, 8, 55-80. http://dx.doi.org/10.1111/j.1527-2001.1993.tb00628.x

Widerberg, K. (1995). Kunskapens kjønn. [The Gender of Knowledge.] Oslo: Pax Forlag. (In Norwegian)

Widerberg, K. (1998). Teaching Gender through Writing “Experience Stories”. Women's International Forum, 21, $193-198$. http://dx.doi.org/10.1016/S0277-5395(98)00002-8

Widerberg, K. (2001a). Introduction. From Exercises to Texts. In K. Widerberg, D. von der Fehr, H. Leira, \& U.-B. Lilleaas (Eds.), Doing Body/Texts: An Explorative Approach (pp. 1-9). Oslo, NO: Department of Sociology and Human Geography, University of Oslo.

Widerberg, K. (2001b). Embodying Intellectuality. In K. Widerberg, D. von der Fehr, H. Leira, \& U.-B. Lilleaas (Eds.), Doing Body/Texts: An Explorative Approach (pp. 10-34). Oslo, NO: Department of Sociology and Human Geography, University of Oslo.

Widerberg, K., Von der Fehr, D., Leira, H., \& Lilleaas, U.-B. (Eds.) (2001). Doing Body/Texts: An Explorative Approach. Oslo, NO: Department of Sociology and Human Geography, University of Oslo. 
Widerberg, K. (2008). For the Sake of Knowledge: Exploring Memory-Work in Research and Teaching. In J. Kaufman, M. S. Ewing, D. Montgomery, \& A. Hyle (Eds.), Dissecting the Mundane: International Perspectives on Memory-Work. Lanham, MD: University Press of America, Inc.

Widerberg, K. (2010). In the Homes of Others: Exploring New Sites and Methods When Investigating the Doings of Gender, Class and Ethnicity. Sociology, 44, 1181-1196. http://dx.doi.org/10.1177/0038038510381604

Widerberg, K (2011). Memory Work: Exploring Family Life and Expanding the Scope of Family Research. Journal of Comparative Family Studies, 42, 329-337.

\section{Submit or recommend next manuscript to SCIRP and we will provide best service for you:}

Accepting pre-submission inquiries through Email, Facebook, LinkedIn, Twitter, etc. A wide selection of journals (inclusive of 9 subjects, more than 200 journals)

Providing 24-hour high-quality service

User-friendly online submission system

Fair and swift peer-review system

Efficient typesetting and proofreading procedure

Display of the result of downloads and visits, as well as the number of cited articles

Maximum dissemination of your research work

Submit your manuscript at: http://papersubmission.scirp.org/ 